\title{
AS METAMORFOSES DE JOYCE: O LABIRINTO NA OBRA UM RETRATO DO ARTISTA QUANDO JOVEM
}

\author{
Luiz. Henrique Raele Braga* \\ Ravel Giordano Paz*
}

RESUMO: A obra Um retrato do artista quando jovem, escrita por James Joyce e publicada em 1916, é um dos marcos da prosa em língua inglesa do século XX, principalmente no campo do Bildungsroman. Acompanhando o desenvolvimento intelectual de seu protagonista, Stephen Dedalus - alter ego de Joyce -, a narrativa se inicia com o personagem ainda criança, e termina quando Stephen alcança o início de sua maturidade, ou seja, quando descobre sua vocação de artista, ou, mais especificamente, de poeta. O presente trabalho, portanto, buscou analisar um dos símbolos identificados no romance, o do labirinto do inventor Dédalo, e como a referida figura mítica acaba por influenciar a própria estrutura da narrativa. Inicia-se com uma breve história da obra, para depois identificar a influência do poeta latino Ovídio - que cantou o mito ora em discussão na sua epopeia Metamorfoses - sobre escritores modernistas de expressão inglesa, limitando-se a abordar, além de Joyce, os poetas T.S. Eliot e Ezra Pound, como forma de contextualizar o uso do poema clássico no início do século XX. Por fim, analisa-se em que medida o símbolo do labirinto pode ser vislumbrado no romance, fazendose o uso, para tanto, de aparato crítico, como os estudos de Ellmann (1989), March (2015), Paris (1992), Parrinder (1984), Levin (1959), entre outros.

PALAVRAS-CHAVE: James Joyce; Modernismo; Ovídio; Labirinto.

\section{Introdução: um autorretrato do artista?}

Publicada em 1916, a obra Um retrato do artista quando jovem, de James Joyce, aborda temas como religião, nacionalismo, política e relações familiares e sociais, bem como o amadurecimento de seu protagonista, Stephen Dedalus, em direção a uma independência artística e intelectual, sendo que este último elemento faz com que se atribua a ela a aura de romance de formação, ou Bildungsroman (KNAUSGÅRD, 2016, P. 12).

Sua trama se desenvolve por meio da fantasia, da percepção e da memória de Stephen (RIQUELME, 1990, p. 66), que se cristalizam através da técnica narrativa do fluxo

\footnotetext{
* Mestrando em Letras pela Universidade Estadual de Mato Grosso do Sul (Uems).

** Professor efetivo de Literatura na Universidade Estadual de Mato Grosso do Sul (Uems). Doutor em Letras Clássicas e Vernáculas (Estudos Comparados de Literaturas de Língua Portuguesa) pela Universidade de São Paulo (Usp).
} 
de consciência - que seria aprofundada no trabalho seguinte de Joyce, Ulysses -, ou monólogo interior, recurso que se torna ainda mais radical quando aplicado em personagem infantil e sem maiores recursos expressivos (LACERDA, 2008, p. 19), pois a história se inicia com Dedalus ainda criança.

De fato, no início, a sintaxe é elementar, composta por orações coordenadas e uma quase total ausência de frases subordinadas, o que cria um efeito infantil de justaposição (LACERDA, 2008, p. 19) e se desenvolve até a juventude do herói, quando então atinge um grau maior de sofisticação.

Segundo o estudo de Caetano W. Galindo,

O desenvolvimento do personagem principal (o alter ego Stephen Dedalus) é o que justifica o amadurecimento da prosa, que de início é confusa como as primeiras lembranças de uma criança pequena e termina com a autossuficiência de um adolescente. (GALINDO, 2016, p. 15)

O tom autobiográfico também figura na obra, projeto fundamental para que o escritor recontasse justamente seu processo de amadurecimento como artista (LACERDA, 2008, p. 18): "se Stephen Dedalus, o personagem que se quer Criador, é ele mesmo uma criação de James Joyce, acontece então um curto-circuito que gera aquilo que em inglês se chama uma self-fulfilling profecy, uma profecia que cumpre a si mesma” (DURÃO, 2008, p. 77), lembrando que a narrativa "está construída sobre uma transcrição literal dos vinte primeiros anos da vida de Joyce" (LEVIN, 1959, p. 49).

Ainda, a ideia de Otto Maria Carpeaux sintetiza a referida mistura da vida do autor com a do mundo ficcional:

[...] se esse naturalista não podia aceitar a realidade da Irlanda, então devia rejeitá-la com violência; e isso aconteceu no romance autobiográfico A Portrait of The Artist as a Young Man, narrado com sutil arte simbolista, mas com tanta violência contra os jesuítas e o catolicismo irlandês que a obra só podia ser publicada depois de Joyce ter saído do país, vivendo no estrangeiro como outlaw. (CARPEAUX, 1984, p. 2.092)

Conforme Richard Ellmann, biógrafo de James Joyce, este, para escrever Um retrato do artista quando jovem, "mergulhou de volta em seu próprio passado, principalmente para 
justificá-lo, mas também para revelá-lo" (1989, p. 370) e, como o próprio escritor explicou a seu irmão Stanislaus, "somos o que fomos, e nossa maturidade é uma extensão de nossa infância" (ELLMANN, 1989, p. 370).

Até mesmo o tema do exílio se encontra nas páginas de Um retrato do artista: Joyce, assim como Dedalus, decide escapar do inferno que era Dublin em 1902, para descobrir em Paris sua vocação de artista (PARIS, 1992, p. 95), sendo que esta junção entre mito e exílio parece ser um dos enfoques cabíveis na referida obra. Portanto, pretende-se no presente trabalho analisar, num primeiro momento, as influências que os mitos antigos, mormente os presentes nas Metamorfoses de Ovídio - cuja biografia também é marcada pelo exílio (DIAS, 2017, p. 34-35) -, exerceram sobre os escritores modernistas, para depois aprofundar o vínculo que Stephen Dedalus, o alter ego de Joyce, mantém com tal mitologia, principalmente no que tange às figuras de Dédalo e do labirinto.

\section{Ovídio e os escritores modernistas}

Muitos foram os artistas que beberam da fonte das Metamorfoses do poeta latino $\mathrm{Pu}-$ blius Ovidius Naso ao longo dos séculos, entre os quais um grande número de escritores e poetas (NETO, 2017, p. 28). Atemo-nos, pois, à análise da referida influência no trabalho de três importantes autores modernistas de expressão inglesa: T. S. Eliot, Ezra Pound e James Joyce.

Quanto a Eliot, em sua monumental Terra devastada (The Waste Land), "cujo tema é a incapacidade do mundo moderno em criar-se de novo" (KIBERD, 2012, p. 51), pode-se ler os seguintes versos:

[...] Acima da lareira antiga se mostrava, Como janela aberta para a cena silvana, Filomela mudada, pelo bárbaro rei Rudemente forçada; mas lá o rouxinol Preenchia o deserto com inviolável voz 
E ainda ela gritava, com ainda o mundo atrás [... $]^{1}$. (ELIOT, 2018, p. 119)

A referida citação compreende o mito de Filomela, narrado no livro VI das Metamorfoses, personagem esta violentada por Tereu, rei da Trácia, além de ter sua língua cortada por ele (MARCH, 2015, p. 102):

[...] Pálida, assustada, tudo temendo e perguntando, já entre lágrimas, onde pode estar a irmã, aí a encerra e, confessando seu crime, viola-a, a ela, virgem e só, $[\ldots]$

Tereu arranca da bainha a espada com que se cingia e, agarrando-a pelos cabelos, com os braços presos atrás das costas, impõe-lhe grilhões. Filomela preparava o pescoço, pois, ao ver a espada,

ficara esperançada na sua morte. A sua língua indigna-se, chama continuamente pelo nome do pai e esforça-se por falar.

Tereu agarra-a com uma tenaz e corta-a com a sua bárbara espada. [...] (OVÍDIO, 2017, p. 349 e 351)

Não menos pungente é a obra central de Pound, Os Cantos (The Cantos), no que se refere a citações à obra máxima de Ovídio (QUINN, 1954, p. 60, tradução nossa); mais do que isso, "as Metamorfoses servem, pois, como instigação temática e técnica a Ezra Pound" (CAMPOS, 1978, p. 198), como é possível vislumbrar no Canto IV, que poetiza o mito de Actéon, que "teria irritado Ártemis quando [...] a viu nua e cercada de ninfas, banhandose [...]; indignada, borrifou-o com a água na qual se banhava e o transformou em veado [...]. Actéon fugiu para a floresta, perseguido por seus ferozes cães de caça" (MARCH, 2015, p. 98):

Nem nódoa, nem solta centelha de sol.

Então Actéon: Vidal,

Vidal. É a voz do velho Vidal

tropeçando no bosque,

Nem mancha, nem mera faísca de sol, 
os cabelos pálidos da deusa.

Os cães saltam sobre Actéon,

"Aqui, aqui, Actéon",

Cervo mosqueado no bosque;

Ouro, ouro, um maço de cabelos,

denso como estriga de trigo,

Arde, arde no sol.

Os cães assaltam Actéon.

Trôpego, tropeçando no bosque,

Murmura, murmura Ovídio [... $]^{2}$. (POUND, 1993, p. 160)

Por fim, Joyce, além de famosamente ter se utilizado de mitos gregos para compor seu Ulysses (KIBERD, 2012, p. 19), baseou-se em um tema da antiguidade greco-latina para compor sua obra Um retrato do artista quando jovem, encontrado nas Metamorfoses:

James Joyce [...] tomou para epígrafe de Retrato do artista quando jovem o verso 188 do Livro VIII, Et ignotas animum dimittit in artes, "entregou-se a artes desconhecidas": Ovídio fala de Dédalo, quando ele está prestes a construir as asas com que fugirá do labirinto. Stephen Dedalus, alter ego de Joyce, também é personagem de Ulisses. (NETO, 2017, p. 29)

A partir da referida epígrafe, o leitor tem consciência do contexto em que a história se desenrola, além do fato de nela haver várias alusões ao mito de Dédalo, como referências a labirintos e, claro, como o próprio nome da personagem central, Stephen Dedalus (THORNTON, 1994, p. 154, tradução nossa). Acerca da história de Dédalo, Stanca (2019, p. 156, tradução nossa) ensina:

2 [...] Not a splotch, not a lost shatter of sunlight.

Then Actaon: Vidal,

Vidal. It is old Vidal speaking,

stumbling along in the wood,

Not a patch, not a lost shimmer of sunlight,

the pale hair of the goddess.

The dogs leap on Actaon,

"Hither, hither, Actcon,"

Spotted stag of the wood;

Gold, gold, a sheaf of hair,

Thick like a wheat swath,

Blaze, blaze in the sun,

The dogs leap on Actaon.

Stumbling, stumbling along in the wood,

Muttering, muttering Ovid [...] (POUND, 1998, p. 14-15) 
Minos, filho de Zeus e de Europa, se recusa a sacrificar um touro branco que lhe fora enviado por Poseidon para este fim. Poseidon o pune fazendo com que sua esposa se apaixone pelo touro branco. Ela faz com que Dédalo, o artesão da corte, construa uma vaca feita de madeira oca, para que ela, encolhida nela, possa consumar sua paixão junto ao touro. Para ocultar sua vergonha, Minos esconde o fruto dessa união, o Minotauro, no labirinto construído por Dédalo. [...] Dédalo construiu um labirinto onde, uma vez lá dentro, homem algum conseguia sair.

Para fugir do labirinto, “junto de seu jovem filho Ícaro, [...] Dédalo inventou asas de cera cobertas de penas com as quais puderam voar para a liberdade longe de Creta" (MARCH, 2015, p. 249). O que ocorre depois, conforme narrado por Ovídio, é que "A proximidade do Sol/ amolece a [...] cera que ligava as penas./ A cera começa a fundir-se. Ícaro bate os braços desnudos,/ mas, sem o batimento das asas, não há ar/ a que se prenda" (2017, p. 431).

O motivo, pois, para os referidos autores criarem suas obras baseando-se nos mitos da antiguidade greco-latina pode ser explicado como uma estratégia, uma "liberação da sensibilidade moderna pelo mito antigo e a ressurreição do mito antigo pela sensibilidade moderna" (KIBERD, 2012, p. 25).

No longo poema de Eliot, por exemplo, tal estratégia pode ser localizada na figura de Tirésias, "o adivinho grego que representa a possível presença unificadora do poema" (GALINDO, 2018, p. 411); utilizando-se do referido mito como uma espécie de dispositivo poético, o autor nos faz ter uma espécie de visão panorâmica de acontecimentos narrados como fragmentos, cacos, visando a uma imagem caótica do mundo no início do século XX, "o deserto espiritual do nosso tempo, [...] profetizando o apocalipse" (CARPEAUX, 2011, p. 2610).

Conforme Declan Kiberd, "os mitos antigos incorporavam a reação imediata das pessoas a sua experiência física e não eram vistos como fictícios por seus adeptos; a nova mitologia, porém, seria abstrata e consciente de seu próprio status fictício” (2012, p. 24/25). E prossegue: 
A necessidade humana de criar mitos é profundamente enraizada, uma vez que os mitos são projeções simbólicas dos valores culturais e morais de uma determinada sociedade, figurações de seu estado psíquico. A Revolução Francesa, que se dispunha a pôr fim na mitografia, instituiu o mito da modernidade, a noção de renovação perpétua que animava espíritos tão diversos quanto os de Ezra Pound ("make it new") e Leon Trótski ("revolução permanente"). (KIBERD, 2012, p. 24)

No caso de Pound, a enorme rede de alusões históricas e mitológicas que se encontram nos seus Cantos "se impôs como o método formal adequado para a mente contemporânea, habituada, pelo desenvolvimento tecnológico dos meios de reprodução e de comunicação, a digerir o máximo de informação no mais breve espaço de tempo" (CAMPOS, 1978, p. 34), lembrando, como ensina Mario Faustino (1977, p. 202), que "os Cantos são o que vê Odisseu, assim como a "Waste Land" é o que Tirésias vê".

Quanto a Joyce, por fim, tem-se que a inscrição de seus romances ( $U m$ retrato do artista quando jovem e, principalmente, o Ulysses) no molde clássico (leia-se, a Odisseia de Homero), com alusões a formas literárias ulteriores, parece significar uma investigação do sentido que tudo isso tem para nós, leitores contemporâneos (ROSENFIELD, 1992, p. 208-209).

Aliás, como bem definido por Declan Kiberd (2012, p. 28), "Seu impulso era sempre o de rebaixar as afirmações mais grandiosas até a dimensão humana, domesticar o épico"; no caso de Um retrato, a atribuição do nome Dedalus ao protagonista parece querer ressaltar que o padrão determinado pelos mitos da antiguidade repete-se com o passar dos tempos - Stephen Dedalus, assim como seu modelo mítico Dédalo, torna-se um artista, nem que para isso tenha que sofrer uma enorme (e simbólica) queda, pois "o desejo universal de ser original não consegue encobrir a realidade de que cada pessoa é uma espécie de cópia, repetindo vidas passadas na inautenticidade de um par de aspas” (KIBERD, 2012, p. 30).

Assim, passemos à análise de um dos mitos engendrados nas Metamorfoses de Ovídio, o labirinto de Dédalo, no contexto de Um retrato do artista quando jovem. 


\section{Dedalus e o labirinto}

Sobre o protagonista Stephen Dedalus, afirma Jean Paris (1992, p. 98) que, "mal se mantém sobre as pernas, a criança já está condenada ao labirinto"; de fato, do início ao ocaso do romance, Stephen se encontrará enredado num imenso (e metafórico) labirinto, representado pela família, pela igreja e pelo contexto social em que vive, qual seja, a Irlanda do início do século XX. A saída, pois, será encontrada somente quando Dedalus se depara com sua verdadeira vocação, a do artista, como o mito de Dédalo, "o habilidoso Dédalo, cuja engenhosidade havia construído o labirinto” (CAMPBELL, 1995, p. 30).

A estrutura dedálica da obra foi observada por alguns pesquisadores. O crítico literário Hugh Kenner descreve o movimento de Um retrato do artista como uma espiral (KENNER apud PARRINDER, 1984, p. 83); já Nicoleta Stanca afirma que os labirintos "fascinam gerações de escritores, historiadores, antropólogos e pesquisadores de todos os tipos, cujos trabalhos podem ter sido bem familiares a Joyce. Eles eram considerados como símbolos da rota tortuosa do inferno" (STANCA, 2019, p. 159). Diane Fortuna, por sua vez, ensina:

Nenhum romance [...] constitui-se de tantas repetições, tantas recapitulações associadas a corredores sinuosos, fios, labirintos; tantas passagens em que o protagonista se encontra como que num ritual de iniciação em cavernas, portões, escadarias, charadas, danças, adivinhações, e finalmente ascenção. (FORTUNA apud STANCA, 2019, p. 159, tradução nossa.)

Ainda, Jean Paris (1992, p. 100), que dedicou um capítulo da sua obra Joyce ao estudo do labirinto em Um retrato do artista, aponta o início dessa referência na infância de Stephen, quando se esconde debaixo da mesa em sua casa diante da repreensão de sua mãe e se desenvolve com sua ida ao colégio jesuíta de Clongowes, quando num determinado dia é empurrado na lama por um garoto. Para Paris, a partir de tais acontecimentos, o personagem "começa a se sentir perdido, [...] e daí para diante a trama vai transcorrer num subterrâneo imenso, onde a luz diminui e se multiplicam os subterrâneos, os cubículos" (1992, p. 100):

Ele se escondeu embaixo da mesa. A mãe dele disse:

- Ah, o Stephen vai pedir perdão. 
A Dante disse:

— Se não pedir, a águia vem e come a mão dele.

Comer a mão

Pedir perdão

Comer a mão

Pedirperdão (JOYCE, 2016, p. 20)

Ele estremeceu como se tivesse água fria e nojenta na pele. Foi maldade do Wells dar um encontrão nele pra ele cair na vala do pátio só porque ele não quis trocar a caixinha de rapé pela castanha da sorte do Wells [...]. Como estava fria e nojenta aquela água! Uma vez um colega viu uma ratazana pular naquele nojo ${ }^{4}$. (JOYCE, 2016, p. 23)

A trama de Um retrato do artista, então, é dividida pelo crítico em labirintos (ou dédalos), sendo o primeiro o demonstrado acima, e os seguintes: o que caracteriza a saída de Stephen de Clongowes e sua volta à cidade (PARIS, 1992, p. 104), “a cidade sombria e brumosa, a casa vazia e sem alegria onde iriam viver dali em diante" (JOYCE apud PARIS, 1992, p. 104); o que desemboca na cena dos prostíbulos, com a "ausência quase total de exteriores [...]. Cada vez mais longe da luz do dia, como que atraído para o próprio núcleo dos infernos, o espírito se afunda, passa naturalmente da noite do bordel para a igreja" (PARIS, 1992, p. 106); e o que, depois, o leva a repudiar todas as ligações mundanas, sendo seu único deus a arte, e sua única moral, a independência (PARIS, 1992, p. 111).

Pode-se, até mesmo, aproximar a estrutura labiríntica de experiências, referendada por Jean Paris, à do Bildungsroman, ou seja, romance de formação; para Weldon Thornton (1994, p. 88-89, tradução nossa),

${ }^{3}$ He bid under the table. His mother said:

- O, Stephen will apologize.

Dante said:

- $O$, if not, the eagles will come and pull out his eyes.

Pull out his eyes,

Apologise,

Apologise,

Pull out his eyes. (JOYCE, 2004, p. 4)

${ }^{4}$ He shivered as if he had cold slimy water next his skin. That was mean of Wells to shoulder him into the square ditch because he would not swop his little snuffbox for Wells's seasoned hacking chestnut [...]. How cold and slimy the water had been! A fellow had once seen a big rat jump into the scum. (JOYCE, 2004, p. 7-8) 
Em cada um dos capítulos Stephen reage a algum chamado, algum impulso, que parece refletir o princípio de vida (significado da vida) que ele busca. No primeiro capítulo, essa cena clímax é seu apelo ao padre Conmee; no segundo, é a visita à prostituta; no terceiro, é sua confissão ao padre; no quarto, sua visão com a garota. Cada uma dessas cenas simboliza para Stephen um senso recém-realizado do que é mais real em sua experiência e, consequentemente, de como ele deve encarar a vida.

Thornton (1994, p. 88-89, tradução nossa) vê nisso uma característica do Bildung, a de que é comum nessa modalidade de romance se ver o protagonista envolvido num movimento oscilatório entre polos de experiência. Tais polos de experiência podem ser vistos sob a ótica simbólica da figura do labirinto, no sentido de se chegar a si mesmo, pois "para o viajante que penetra no labirinto, a meta é atingir a câmara central, a cripta dos mistérios. Mas, ao atingi-la, deve sair e regressar ao mundo exterior, atingir [...] um novo nascimento" (BRION apud PARIS, 1992, p. 99). Conforme o "Dicionário de Símbolos",

O labirinto também conduz o homem ao interior de si mesmo, a uma espécie de santuário interior e escondido, no qual reside o mais misterioso da pessoa humana. Pensa-se aqui em mens, templo do Espírito Santo na alma em estado de graça, ou ainda nas profundezas do inconsciente. Um e outro só podem ser atingidos pela consciência depois de longos desvios ou de uma intensa concentração, até esta intuição final e que tudo se simplifica por uma espécie de iluminação. É ali, nessa cripta, que se reencontra a unidade perdida do ser, que se dispersara na multidão dos desejos. (CHEVALIER; GHEERBRANT, 2019, p. 531)

Tal aproximação interpretativa entre a personagem e o símbolo é válida. Para Anthony Burgess (1994, p. 48), na obra em análise o símbolo "fundamental é o de uma criatura que tenta escapar do cativeiro dos elementos mais espessos, terra e água, e aprende dolorosamente a voar" - Dédalo, o inventor, criou asas de cera cobertas de penas com as quais voou para a liberdade -, sendo que "o leitmotiv dedálico do voo é representado em várias imagens de pássaros e morcegos que surgem na consciência de Stephen” (PARRINDER, 1984, p. 82) ao longo do romance. Aliás, “escapar” parece ser o objetivo de Stephen, como se escapa de um labirinto: 
Stephen se verá aprisionado na casa da sua família, na religião e em seu país, e as visões que tem a respeito de pássaros em momentoschave do romance são simbólicas no que toca à sua vontade de voar e escapar. As imagens de voo estão contidas nas referências ao mito de Dédalo (o homem com asas), pássaros, morcegos e Lúcifer; personagens possuem nomes de pássaros (Cranley, Heron); a águia vai arrancar o olho do menino se ele desobedecer [...]. (STANCA, 2019, p. 156, tradução nossa)

O próprio Stephen afirma ser "diferente dos outros [...]” e que "não queria brincar. Queria encontrar no mundo real a imagem insubstancial que sua alma contemplava com tanta constância" (JOYCE, 2016, p. 86). No entanto, há toda uma série de obstáculos concretos em seu caminho, conforme acima já mencionado:

[...] ir andando, mas não para o corredor, e sim escadaria acima à direita, para o castelo. Só precisava fazer isso: virar à direita e andar rápido escada acima e em meio minuto estaria no longo corredor estreito e escuro que atravessava o castelo até a sala do reitor. [...] Subiu velozmente os degraus que saíam do jardim, receando que certa presa lhe escapasse, e abriu caminho à força entre a multidão para entrar no saguão passando pelos dois jesuítas que guardavam o êxodo e faziam reverências e apertavam as mãos dos visitantes. [...] Ele retomou sua errância. As veladas noites de outono o levavam de rua em rua como o tinham levado anos antes pelas silenciosas avenidas de Blackrock55. (JOYCE, 2016, p. 73, 110 e 126)

Além desses, existem também obstáculos mais abstratos e que guardam um certo grau de subjetividade, por serem compostos de construções sociais, como a família, a religião e o nacionalismo, por exemplo:

- A alma nasce - ele disse vagamente - primeiro naqueles momentos de que eu te falei. Ela tem um parto lento e negro, mais misterioso que o do corpo. Quando a alma de um homem nasce

${ }^{5}[. .$.$] to go on walking but not out to the corridor but up the staircase on the right that led to the castle. He had nothing to do but$ that; to turn to the right and walk fast up the staircase and in half a minute be would be in the low dark narrow corridor that led through the castle to the rector's room. [...] He mounted the steps from the Garden in haste, eager that some prey should not elude him, and forced his way through the crowd in the hall and past the two jesuits who stood watching the exodus and bowing and shaking hands with the visitors. [...] He returned to his wanderings. The veiled autumnal evenings led him from street to street as they had led him years before along the quiet avenues of Blackrock. (JOYCE, 2004, p. 47, 75, 87) 
nesta terra, ela encontra redes lançadas para impedir seu voo. Você me fala de nacionalidade, língua, religião. Eu vou tentar voar e escapar dessas redes ${ }^{6}$. (JOYCE, 2016, p. 249)

Stephen, no final da obra, alcança seu objetivo de exilar-se em relação às referidas “redes”. Conforme ensina Hodgart (1983, p. 57, tradução nossa), o artista para Joyce é um "homem separado dos outros pela sua vocação, e deve lutar para se separar das amarras da família, da comunidade e de sua nacionalidade, que o prendem no lugar-comum, num mundo burguês"; some-se a isso a instituição da igreja, o que atesta o seguinte excerto da obra ora em estudo:

Eu não vou servir àquilo em que não acredito mais, possa essa coisa se dizer minha casa, minha pátria ou minha Igreja: e eu vou tentar me expressar em algum modo de vida ou de arte com a liberdade que eu conseguir e com a plenitude que eu conseguir, usando em minha defesa as únicas armas que eu me permito usar - silêncio, exílio e astúcia7. (JOYCE, 2016, p. 301)

Assim, Stephen consegue fugir dos labirintos da nacionalidade e da religião por meio da arte (STANCA, 2019, p. 161), mais especificamente através da literatura:

Stephen enfim sabe que a literatura é sua vocação, sacerdotal o bastante, já que sua função é a transmutação de acidentes inferiores em essência divina. Por intermédio da arte ele consegue lidar com os conteúdos baixos da vida material. (BURGESS, 1994, p. 56)

\section{Considerações finais}

Obra permeada de símbolos (os quais, infelizmente, não puderam ser exauridos neste trabalho), Um retrato do artista quando jovem é Joyce se preparando para suas posteriores experimentações na linguagem em Ulysses e Finnegans Wake. A simbologia utilizada na obra em questão fica inteiramente a serviço de Stephen e sua introspecção perante a vida.

${ }^{6}$ _ The soul is born, he said vaguely, first in those moments I told you of. It has a slow and dark birth, more mysterious than the birth of the body. When the soul of a man is born in this country there are nets flung at it to bold it back from flight. You talke to me of nationality, language, religion. I shall try to fly by those nets. (JOYCE, p. 179-180, 2004)

${ }^{7}$ I will not serve that in which I no longer believe, whether it call itself my home, my fatherland or my church: and I will try to express myself in some mode of life or art as freely as I can and as wholly as I can, using for my defence the only arms I allow myself to use, silence, exile and cunning. (JOYCE, p. 219, 2004) 
Conforme colocado alhures, o "caminho tortuoso do inferno" pelo qual passa o personagem leva-o a uma tomada de consciência de si e do mundo, um caminho que se inicia no cativeiro, na lama, passando pela culpa até atingir a redenção final, sua ascensão ao papel de artista: segundo o próprio Joyce, "a obra de arte, como o amor de mãe, deve ser obtida ultrapassando-se os maiores obstáculos" (ELLMANN, 1989, p. 370).

Forçoso concluir, portanto, que a narrativa-labirinto, conforme trabalhada acima, possui uma estrutura que leva a um centro, ou seja, a um encontro com o si-mesmo, e também à "transformação do eu, que se opera no centro do labirinto e que se afirmará à luz do dia no fim da viagem de retorno, no término, dessa passagem das trevas à luz" (CHEVALIER; GHEERBRANT, 2019, p. 532).

\title{
JOYCE'S METAMORPHOSES: THE LABYRINTH IN THE NOVEL $A$ POR- TRAIT OF THE ARTIST AS A YOUNG MAN
}

\begin{abstract}
The novel $A$ portrait of the artist as a young man, written by James Joyce and published in 1916, is one of the marks of prose in the 20th century English language, mainly in the field of Bildungsroman. Following the intellectual development of its protagonist, Stephen Dedalus - Joyce's alter ego, the narrative starts with the character as a child, and ends when Stephen reaches the beginning of his maturity, that is, when he discovers his vocation as an artist, or more specifically, as a poet. The present work, therefore, sought to analyze one of the symbols identified in the novel, that of the labyrinth of the inventor Dedalus, and how that mythical figure ends up influencing the very structure of the narrative. It begins with a brief history of the work, to later identify the influence of the Latin poet Ovid - who sang the myth now under discussion in his epic Metamorphoses - on English-speaking modernist writers, limited to approaching, besides Joyce, the poets TS Eliot and Ezra Pound, as a way to contextualize the use of the classic poem in the early 20th century. Finally, it analyzes the extent to which the symbol of the labyrinth can be seen in the novel, making use of a critical apparatus, as in the studies of Ellmann (1989), March (2015), Paris (1992), Parrinder (1984), Levin (1959), among others.
\end{abstract}

KEY-WORDS: James Joyce; Modernism; Ovid; Labyrinth.

\section{REFERÊNCIAS}

BRION, Marcel apud PARIS, Jean. Joyce. Rio de Janeiro: José Olympio, 1992.

BURGESS, Anthony. Homem Comum Enfim : uma introducão a James Joyce para o leitor comum. São Paulo: Companhia das Letras, 1994.

CAMPBELL, Joseph. O Herói de mil faces. São Paulo: Cultrix/Pensamento, 1995. 
CAMPOS, Augusto de. In: POUND, Ezra. POESLA/ Eq̧ra Pound; introdução, organização e notas de Augusto de Campos. São Paulo: HUCITEC; Brasília: Editora da Universidade de Brasília, 1993.

CARPEAUX, Otto Maria. História da Literatura Ocidental. São Paulo: Leya, 2011.

CHEVALIER, Jean; GHEERBRANT, Alain. Dicionário de Símbolos. Rio de Janeiro: José Olympio, 2019.

DIAS, Domingos Lucas. Nota introdutória. In: OVÍDIO. Metamorfoses. São Paulo: Editora 34, 2017.

DURÃO, Fabio Akcelrud. Fome de Ordem. Revista Entre Livros n. 9. São Paulo: Duetto Editorial, 2008.

ELIOT, Thomas Stearns. Collected Poems : 1909-1935. London: Faber \& Faber Limited, 1949.

. Poemas. São Paulo: Companhia das Letras, 2018.

ELLMANN, Richard. James Joyce. São Paulo: Globo, 1989.

FAUSTINO, Mario. Poesia-experiência. São Paulo: Perspectiva, 1977.

FORTUNA, Diane apud STANCA, Nicoleta. Ovid, Myth and Exile in James Joyce's A portrait of the artist as a young man. Disponivel em http://litere.univ-ovidius.ro/TRANS-

MIT/documente/ovid_conf_proc/19_Stanca.pdf. Acesso em: 01 fev. 2020.

GALINDO, Caetano. Posfácio. In: ELIOT, Thomas Stearns. Poemas. São Paulo: Companhia das Letras, 2018.

. Introdução. In: JOYCE, James. Um retrato do artista quando jovem. São Paulo: Companhia das Letras, 2016.

HODGART, Matthew. James Joyce. Londres: Routledge \& Kegan Paul, 1978.

JOYCE, James. A portrait of the artist as a young man. New York: Barnes \& Noble Classics, 2004.

JOYCE, James. Um retrato do artista quando jovem. São Paulo: Companhia das Letras, 2016. KENNER, Hugh apud PARRINDER, Patrick. James Joyce. Cambridge: Cambridge University Press, 1984.

KIBERD, Declan. Introdução. In: JOYCE, James. Ulysses. São Paulo: Penguin Classics Companhia das Letras, 2012.

KNAUSGÅRD, Karl Ove. Introdução. In: JOYCE, James. Um retrato do artista quando jovem. São Paulo: Penguin Classics Companhia das Letras, 2016. 
LACERDA, Rodrigo. Individualidade contra religião. Revista Entre Livros n. 9. São Paulo: Duetto Editorial, 2008.

LEVIN, Harry. James Joyce. México, D.F.: Fondo de Cultura Económica, 1959.

MARCH, Jenny. Mitos Clássicos. Rio de Janeiro: Civilização Brasileira, 2015.

NETO, João Angelo Oliva. Apresentação. In: OVÍDIO. Metamorfoses. São Paulo: Editora 34, 2017.

OVÍDIO (Publius Ovidius Naso). Metamorfoses. São Paulo: Editora 34, 2017.

PARIS, Jean. Joyce. Rio de Janeiro: José Olympio, 1992.

PARRINDER, Patrick. James Joyce. Cambridge: Cambridge University Press, 1984.

POUND, Ezra. POESLA/ Ezra Pound; introdução, organização e notas de Augusto de Campos. São Paulo: HUCITEC; Brasília: Editora da Universidade de Brasília, 1993. . The Cantos of Ezra Pound. New York: New Directions, 1998.

QUINN, Sister M. Bernetta. The Metamorphoses of Ezra Pound. In: LEARY, Lewis (ed.). Motive and method in the Cantos of Eqra Pound. New York: Columbia University Press, 1961.

RIQUELME, John Paul. Stephen Hero, Dublinenses e Retrato do Artista Quando Jovem: Estilos de Realismo e Fantasia. In: NESTROVSKI, Arthur (org.). riverrun: Ensaios sobre James Joyce. Rio de Janeiro: Imago Ed., 1992.

ROSENFIELD, Kathrin Holzermayr. Dedalus, ou as Metamorfoses do Trágico em Ulysses. In: NESTROVSKI, Arthur (org.). riverrun: Ensaios sobre James Joyce. Rio de Janeiro: Imago Ed., 1992.

STANCA, Nicoleta. Ovid, Myth and Exile in James Joyce's A portrait of the artist as a young man. Disponível em http://litere.univ-ovidius.ro/TRANSMIT/documente/ovid_conf_proc/19_ Stanca.pdf. Acesso em: 01 fev. 2020.

THORNTON, Weldon. The Antimodernism of Joyce's A Portrait of the Artist as a Young Man. Syracuse, NY: Syracuse University Press, 1994.

Recebido em: 30/11/2020. Aprovado em: 15/01/2021. 